Thorax (1969), 24, 629.

\title{
Entire left atrial myxoma presenting as a saddle embolus
}

\author{
M.KULKAR N I, I. MCD. JESSIMAN,ANDS. FRENCH \\ From the Thoracic Surgical Unit, Papworth Hospital, Papworth Everard, Cambridgeshire, and the \\ Peterborough District Hospital, Peterborough
}

A case is presented in which a complete left atrial myxoma became detached and lodged in the aortic bifurcation. Shortly after it had been removed the patient suffered cardiac arrest and could not be revived.

The occurrence of saddle embolism of the aorta resulting from total expulsion of a left atrial myxoma is rare. Only five previous cases have been recorded. Three of them died-one without surgery within a few hours, one in the operating theatre, and the third on the ninth post-operative day. The other two cases survived following embolectomy.

Brewin (1951) was the first to record a case in which the whole myxoma had embolized, without fragmentation, to the aortic bifurcation.

Carter, Lowe, and Hill (1960) reported a case of aortic embolism in a woman of 60 , in whom surgical removal of the embolus, consisting of 'typical myxomatous tissue', was followed by recovery. No intra-atrial tumour could be seen on angiography during convalescence, and the patient was well eight months later.

In the case presented by Silverman, Olwin, and Graettinger (1962) several emboli seem to have occurred before the main tumour became detached and lodged at the aortic bifurcation. Embolectomy was performed but the patient died in renal failure on the ninth post-operative day. At necropsy a small tumour pedicle was found in the left atrium and tumour emboli and infarcts were found in the liver, spleen, left kidney, and right cerebral artery.

Guthrie and Fairgrieve's (1963) case was a man of 57 who had an aortic embolus, without any previous symptoms of heart disease, the cause being a partly calcified myxoma from the left atrium which lodged in the abdominal aorta just below the diaphragm. Irreversible ventricular fibrillation occurred during attempted embolectomy.

Bruneau and Stanley (1965) record a man of 50 who presented with a sudden paraplegia due to an embolus at the aortic bifurcation. A myxoma was removed from this site and found to be complete, including its pedicle. Nine months later he suffered a left hemiplegia and angiography revealed a filling defect in the left atrium. At operation three myxomata were found in the atrium and these were successfully removed.

\section{CASE REPORT}

A 61-year-old man, while out walking, experienced palpitation and faintness, followed by a painful sensation in his legs as if hot water were being poured over them. His legs also began to feel heavy, became weak, and gave way. The pain gradually centred in the hypogastric region with complete loss of power and sensation below this level.

In 1963 he had attended hospital as an out-patient on account of a mental disturbance, complaining of lack of concentration, lack of fluency in speech, palpitation, and loss of weight. He was considered to be suffering from depression and was successfully treated with amitriptyline. About four months before death he had had a bout of headache, giddiness, and diffculty in using his right arm and leg. This hemiparesis had incompletely resolved over about six weeks.

When examined on arrival at hospital he was mentally alert and coherent, but pale, sweating, and in pain. His pulse rate was $80 /$ minute and regular; his blood pressure $120 / 80 \mathrm{~mm}$. Hg. A short apical systolic murmur was audible. Both legs were cold, pulseless, paralysed, and anaesthetic. No reflexes could be elicited in these limbs. No aortic pulsation could be felt in the abdomen.

His electrocardiogram showed a normal sinus rhythm with a $\mathbf{P}$ pulmonale. A pre-operative radiograph of the chest showed a normal heart size but some evidence of pulmonary congestion.

The diagnosis of saddle embolus was made and the possibility of a myxoma as the source of this embolus was considered.

Operation was begun about six and a half hours 


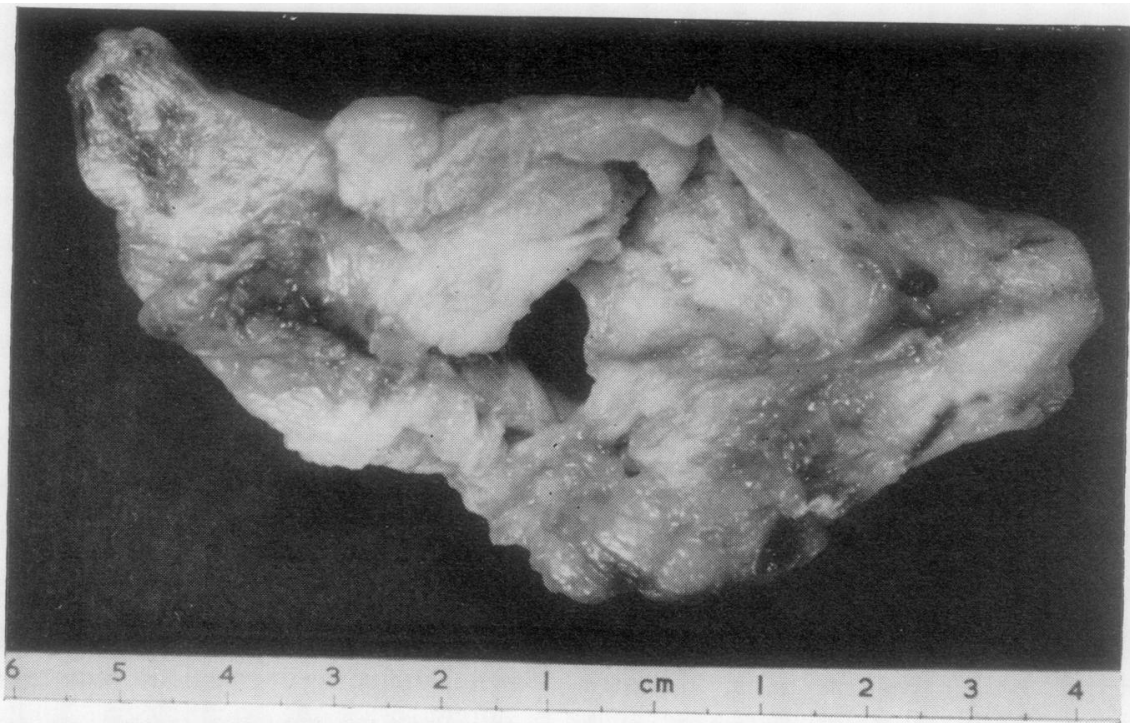

FIG. 1. The myxomatous embolus.

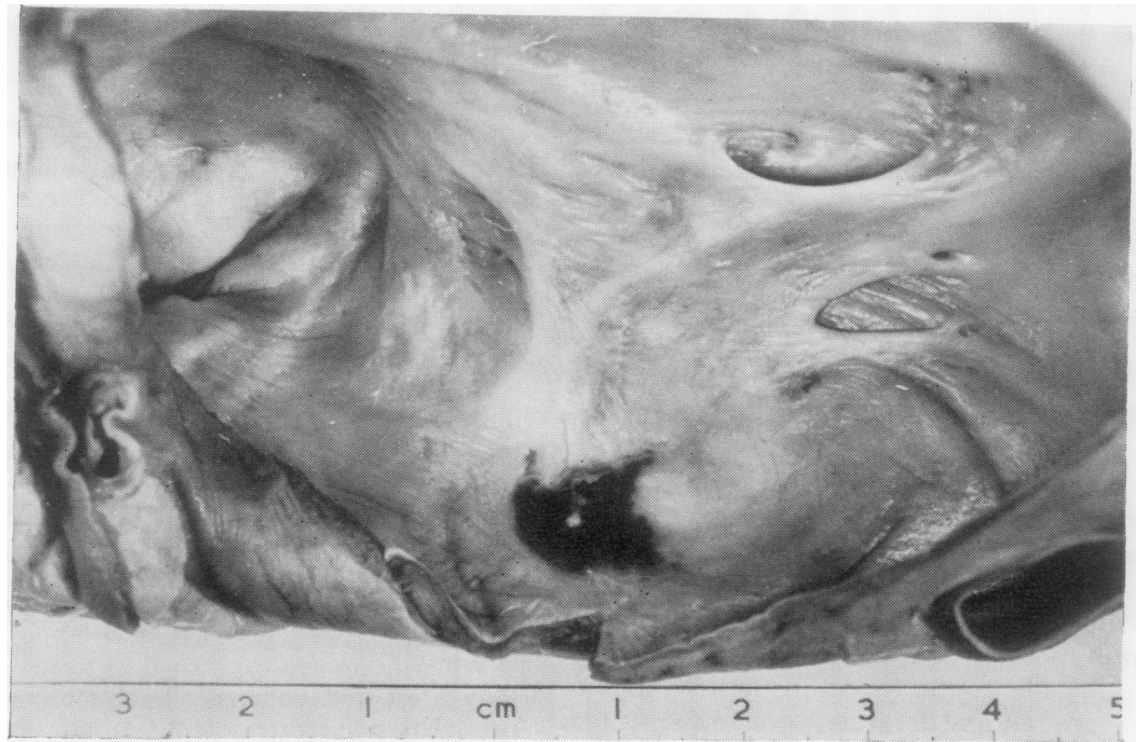

FIG. 2. Recent thrombus on the posterior wall of the left atrium (site of attachment of the myxoma).

after his collapse. An attempt to remove the saddle embolus with Fogarty catheters via bilateral common femoral arteriotomies failed to dislodge any clot. This strongly supported the pre-operative suspicion that a myxoma might be the cause of the embolus. A laparotomy was performed through a transverse hypogastric incision and after clamping the aorta and both common iliac arteries an arteriotomy was made in the right common iliac artery and lower aorta.
A yellowish mass with a smooth surface was grad ally extracted from both common iliac arteries an the aorta (Fig. 1). It measured $10 \times 6 \mathrm{~cm}$., and of inspection two holes in it, made by the Fogarty catheters, were noted. At the opposite end of the mass was a small piece of purplish material which appeared to be part of the atrial wall. The vascular incisions were sutured and the clamps released shortly afterwards he had a cardiac arrest and could 
not be resuscitated. Necropsy failed to reveal any obvious cause for his cardiac arrest.

NECROPSY There was an area of recent thrombus, $1 \mathrm{~cm}$. in diameter, on the posterior wall of the left atrium, $2 \mathrm{~cm}$. above the mitral ring, at the junction of the inter-atrial septum (Fig. 2). The left atrium was more dilated than the right and it measured approximately $3 \times 6 \mathrm{~cm}$. There were bilateral pleural effusions of $40 \mathrm{ml}$. with considerable oedema of both upper lobes. He had an intra-splenic calcified arterial aneurysm. The brain showed left parietal convolutional atrophy. Histological examination confirmed that the tumour consisted of myxomatous tissue.

\section{DISCUSSION}

In recent years myxomata of the heart have been increasingly recognized, studied, and successfully treated (Goodwin, 1968; Greenwood, 1968 ; Harvey, 1968 ; Heath, 1968). Saddle embolism has been an uncommon presentation among the published cases, now over 400 in number, and detachment of a complete myxoma even rarer.

The embolic effects of cardiac myxomata are varied. Emboli from left atrial myxomata are frequently multiple (Goodwin, 1963) and may occur in any systemic vessel, including the coronary arteries. Cerebral emboli are the most common (Aldridge and Greenwood, 1960), but it is rare for them to occur in isolation (Silverman et al., 1962). Large emboli lodging in the aorta, at the bifurcation, or above, are not uncommon and may follow other emboli (Gleason, 1955 ; Gerbode, Osborn, Robson, Braimbridge, and Hultgren, 1958 ; Silverman et al., 1962 ; Casolo, Manzocchi and Parini, 1964 ; Newman, Cordell, and Prichard (2 cases), 1966 ; Mundth, Wheeler, Moses, and Austen, 1968) or occur without premonitory symptoms (Brewin, 1951 ; Edwards and Johnson, 1959 ; Carter et al. (2 cases), 1960 ; Guthrie and Fairgrieve, 1963 ; Soriano, Berry, and Shea, 1964 ; Bruneau and Stanley, 1965). In most cases, however, the further course of events has revealed that part of the tumour has been left in situ.

In our case the history of palpitation and mental disturbance in 1963 (cf. Newman et al., 1966 (case 4) ) and of a right hemiparesis in 1968, together with the necroscopy finding of left parietal convolutional atrophy, suggested that other emboli had been shed by the myxoma, though not recognized at the time.

The cause of death, which took place in a manner very similar to that of the case reported by Guthrie and Fairgrieve (1963) remains uncertain. Ventricular fibrillation may have occurred initially, although by the time a recording had been obtained the tracing was one of asystole. Hyperkalaemia or gross acidaemia following reestablishment of the circulation to the ischaemic lower half of the body are possible explanations. On the other hand, release of the aortic clamps may have produced transient hypotension and critically reduced the coronary flow.

We wish to thank Dr. K. D. Allanby, Mr. B. B. Milstein, and Dr. P. G. I. Stovin for their valuable help in publishing this paper.

\section{REFERENCES}

Aldridge, H. E., and Greenwood, W. F. (1960). Myxoma of the left atrium. Brit. Heart J., 22, 189.

Brewin, T. B. (1951). 'Myxoma' of the heart. Guy's Hosp. Rep., 100, 278.

Bruneau, L., and Stanley, P. (1965). Myxome cardiaque. Un. méd. Can., 94, 697.

Carter, A. Barham, Lowe, K. G., and Hill, I. G. W. (1960). Cardiac myxomata and aortic saddle embolism. Brit. Heart J., $22,502$.

Casolo, G., Manzocchi, L., and Parini, F. (1964). Il mixoma dell' atrio sinistro. Osped. maggiore, 59,1

Edwards, A. T., and Johnson, W. (1959). A case of myxoma of the left atrium with peripheral arterial emboli. Brit. J. Surg., 46, 371.

Gerbode, F., Osborn, J. J., Robson, G. B., Braimbridge, M., and Hultgren, H. (1958). Left atrial myxoma: successful removal with the aid of extracorporeal circulation. Ann. Surg., 147, 320.

Gleason, I. O. (1955). Primary myxoma of the heart: a case simulating rheumatic and bacterial endocarditis. Cancer (Philad.), 8, 839.

Goodwin, J. F. (1963). Diagnosis of left atrial myxoma. Lancet, 1, 464. (1968). The spectrum of cardiac tumors. Amer. J. Cardio!., 21, 307.

Greenwood, W. F. (1968). Profile of atrial myxoma. Ibid., 21, 367.

Guthrie, J., and Fairgrieve, J. (1963). Aortic embolism due to myxoid tumour associated with myocardial calcification. Brit. Heart J., $25,137$.

Harvey, W. P. (1968). Clinical aspects of cardiac tumors. Amer. J. Cardiol., 21, 328.

Heath, D. (1968). Pathology of cardiac tumors. Ibid., 21, 315.

Mundth, E. D., Wheeler, E. O., Moses, J. M., and Austen, W. G. (1968). Clinical aspects of left atrial myxoma. Report of a case simulating subacute bacterial endocarditis and review of 5 cases treated surgically. Ann. thorac. Surg., 5, 255.

Newman, H. A., Cordell, A. R., and Prichard, R. W. (1966). Intracardiac myxomas. Literature review and report of six cases, one successfully treated. Amer. Surgn, 32, 219.

Silverman, J., Olwin, J. S., and Graettinger, J. S. (1962). Cardiac myxomas with systemic embolization. Review of the literature and report of a case. Circulation, 26, 99 .

Soriano, F. M., Berry, R. W., and Shea, J. P. (1964). Experiences with arterial tumor embolism. St. Vincent's Hosp. Med. Bull. (Bridgeport ), 6, 33. 